\title{
DELS MANUSCRITS MEDIEVALS APAREGUTS I RETROBATS DE LA BIBLIOTECA DE LA REIAL ACADÈMIA DE BONES LLETRES DE BARCELONA
}

\author{
LOURDES SORIANO ROBLES
}

\begin{abstract}
This paper reviews the vicissitudes experienced by the library of the Reial Acadèmia de Bones Lletres de Barcelona since its inception in the eighteenth century to the present. As it has been generally stated, the collections of the library and archive constitute a basis for studying the activities of this institution and the cultural, artistic and literary milieu of the eighteenth century; but beyond that, the library holds some medieval manuscripts preserved thanks to the efforts undertaken by some scholars and members of the academy to safeguard the books from the confiscation of church properties after the exclaustration and the burning of convents during the years I 835 -I 836 . Therefore, one of the main goals of this paper is to focus on these medieval witnesses, their codicological analysis and literary content, and finally to trace their conventual origin, a process that has been possible in part thanks to the testimony of father Jaime Villanueva and his Viage literario a las iglesias de España (1803-I854).
\end{abstract}

\section{INTRODUCCIÓ}

F a uns quants anys, estudiant per a BITECA (la Bibliografia de Textos Catalans Antics) ${ }^{\mathrm{I}}$ un exemplar fragmentari de la Vita Christi de Francesc Eiximenis que es conserva a la biblioteca de la Reial Acadèmia de Bones Lletres de Barcelona, Glòria Sabaté i jo mateixa el vàrem identificar com un testimoni retrobat d'un dels dos exemplars que es donen encara per desapareguts des de la Guerra Civil i que formaven part de l'arxiu del Palau Requesens a Barcelona (Soriano i Sabaté).

Ara, revisant novament els testimonis medievals d'aquesta biblioteca, s'ha arribat a la conclusió que el manuscrit de l'obra del menoret no pot ser, per raons codicològiques, un d'aquests dos testimonis perduts, sinó que es tractaria d'un còdex diferent. Prenent aquest fet com a fil conductor, el propòsit d'aquest treball no és altre que resseguir les vicissituds de la biblioteca de la Reial Aca-

${ }^{1}$ Aquesta investigació s'ha desenvolupat dins d'aquest projecte, ref. FFI2008-03882 del Ministerio de Ciencia y Tecnología, cofinançat amb fons FEDER. Hom pot consultar les dades al web de BITECA: <http://sunsite.berkeley.edu/Philobiblon>. S'ha d'advertir, però, que les dades que hi apareixen no estan actualitzades perquè s'està treballant en la nova versió; per això les descripcions dels manuscrits incloses en el present treball responen a una revisió actual pendent de ser-hi incorporada. En aquest sentit, el fragment eiximenià encara apareix sota «Barcelona: olim Biblioteca del Palau Requesens» en comptes de «Barcelona: Biblioteca de Bones Lletres». 
dèmia de Bones Lletres des dels seus orígens i els seus fons medievals per tal de poder escatir la procedència d'aquest manuscrit, així com la dels altres testimonis medievals que preserva aquesta corporació barcelonina.

\section{BREUS APUNTS SOBRE LA HISTÒRIA DE LA BibliotecA de laReial Acadèmia de Bones Lletres de Barcelona}

La Reial Acadèmia de Bones Lletres de Barcelona posseeix avui dia un arxiu i una biblioteca, a banda d'un museu, fonamentals per a l'estudi de les activitats de la institució i del moviment cultural, artístic i literari del segle xviII. ${ }^{2}$

La primera notícia de l'existència de l'arxiu data de l'I de maig de 1729, uns anys després de la creació de la llavors Acadèmia dels Desconfiats, per tal de preservar les actes de les sessions, els discursos dels acadèmics i tota altra documentació corporativa.

Les primeres notícies existents, però, sobre la necessitat de crear una biblioteca són més tardanes i es remunten a l'any i 833 , justament quan l'Acadèmia torna a ser restablerta i reorganitzada per iniciativa de l'Ajuntament de Barcelona, després d'anys de suspensió d'activitats per Reial Ordre del I 824 de $\mathrm{Fe}-$ rran VIII. Comença, llavors, una nova etapa sota la direcció de Pròsper de Bofarull i la secretaria a càrrec de Ramon Muns, durant la qual es pretén continuar vells projectes de caire històric i lingüístic, com la redacció d'una Història de Catalunya o la composició d'una gramàtica i un diccionari de la llengua catalana, i s'obren pas d'altres de més ambiciosos, entre els quals destaca la voluntat de restauració de la Universitat, un gran anhel cultural en el qual l'entitat intervingué decisivament.

Durant aquest nou període d'activitat, l'Acadèmia, en efecte, pren consciència de la seva missió cultural i acadèmica i sorgeix un viu interès per la creació d'un museu i una biblioteca propis on es conservin peces artístiques i els llibres i publicacions, o fons llegats per acadèmics; hom destaca, per exemple, d'aquesta època la donació del rar incunable de la Gramàtica de Mates per part de Jaume Ripoll el I 835 (Riquer 297).

És precisament durant aquest any que la missió de l'Acadèmia com a entitat preocupada per salvaguardar el patrimoni artístic i cultural català pren més sentit. La desamortització dels béns eclesiàstics i l'exclaustració i crema de convents durant els anys I 835-I836 preocuparen molt els acadèmics. Com explica Duran i Sanpere (559), encara fumejaven les ruïnes quan l'Ajuntament s'afanyà

${ }^{2}$ Vegeu, per a una història de la corporació barcelonina, M. de Riquer (I953), A. Comas (1964) i M. Campabadal (2007). L'únic treball que ens consta sobre la biblioteca és el que signa l'acadèmic F. Mateu i Llopis (I953) que assaja d'explicar la creació de la biblioteca i la seva evolució fins a començaments del segle xx, però les dades que ofereix d'aquesta secció apareixen entrellaçades amb les de l'arxiu i el museu, per la qual cosa a vegades es fa impossible discernir quan parla d'una secció o de l'altra, tot i que tenim present que l'evolució de la biblioteca i del museu, per exemple, a vegades corren paralleles, comparteixen seu i s'enriqueixen a partir de la desamortització de Mendizábal. 
a salvar el que es pogués, fossin elements arquitectònics, peces artístiques o llibres i documents. Es formaren diversos grups de veïns, als quals s'afegí l'Acadèmia barcelonina i, davant de la gran quantitat de llibres que arribaren a reunir-se, el governador interí, José Melchor Prat, hagué d'intervenir i, en compliment de la Reial Ordre del 29 de juliol de i 835, constituí el 24 d'agost una comissió provincial, a la qual s'integraren alguns membres de l'Acadèmia, que dugué a terme la recollida i inventari de tot aquell tresor bibliogràfic arreplegat dels convents suprimits (Alcolea et al. 28). La voluntat de l'Ajuntament, tal com després informà en sessió extraordinària de l'i de juliol de 1836 , no era altra que formar una biblioteca general pública en algun dels edificis que havien quedat lliures, sota els auspicis del mateix consistori.

El manuscrit I 522 de Reserva de la Biblioteca de la Universitat de Barcelona (Miquel Rosell 4: I9) és un esborrany redactat per la comissió de l'inventari dels llibres recollits en vint-i-quatre convents i collegis de religiosos de la ciutat de Barcelona i d'altres poblacions properes. Sumen un total de I 33.855 volums que inicialment foren dipositats al convent dels caputxins de la Rambla, on romangueren poc temps, per ser traslladats més tard al convent de Sant Joan de Jerusalem, que es trobava al costat de l'actual Via Laietana.

Paralllelament, l'Acadèmia, que fins llavors no disposava d'unes dependències pròpies, amb l'exclaustració de convents veié la possibilitat de fer-se amb una seu, de manera que aspirava a aconseguir la cessió d'algun convent, en especial el dels agustins. El desembre de I 835, la Junta de Enajenación de Conventos comunicà que havia decidit cedir interinament el monestir de Sant Joan a l'Acadèmia i a la Sociedad Económica de Amigos del País, tot compartint les dependències, i la corporació s'hi traslladà durant els darrers mesos de i 835 i el març de I836. Un cop installlats, en la sessió del 22 de març, a petició de l'acadèmic Antoni Montmany, s'acordà dirigir una sollicitud a la reina governadora, Maria Cristina de Borbó, i al governador civil per tal que l'Acadèmia fos autoritzada a recollir $i$ tenir cura dels papers, manuscrits $i$ impresos rars trobats en monestirs i convents suprimits, per tal de preservar-los de la pèrdua i la destrucció, perquè, com referia Montmany durant la reunió:

Se encuentran hacinados y revueltos en el local de San Juan, corriendo gran riesgo de perderse y destruirse por la humedad y los ratones, para atender a su clasificación y publicar los dignos de ver la luz... por ser esta Academia la única corporación literaria del Principado que puede con fruto recoger, conservar y hacer uso de dichas preciosidades para los objetos de su instituto (Alcolea et al. 28). ${ }^{3}$

3 Parallelament, davant de la imminent destrucció dels convents barcelonins de Santa Caterina i Sant Francesc, l'Acadèmia acordà, en la sessió de 8 de novembre de i 836, a petició del secretari, Ramon Muns, dirigir-se a la Junta de Enajenación de Conventos demanant que abans de l'enderroc d'aquestes dues cases religioses es permetés a la corporació inspeccionar i salvar «sepulcres, estàtues, inscripciones en lemosín, y objetos artísticos». En sessió celebrada el dia 6 de desembre, l'acadèmic Pi i Aramon informava que la comissió designada per l'Acadèmia havia recollit els objectes artístics dels dos convents. Veg. Mateu i Llopis (483) i Riquer (296-297). 
El I 2 de juny d'aquest mateix any i 836 , la sollicitud fou informada favorablement i, com comunicà Pròsper de Bofarull en sessió acadèmica, el Ministeri de la Governació atorgava per reial ordre a l'Acadèmia la custòdia dels manuscrits trobats que tinguessin relació amb la història i antiguitats catalanes i nomenava la comissió, formada pels acadèmics Josep Antoni Llobet i Vall-llosera, Andreu Avelllí Pi i Aramon i Joan Cortada i Sala, que s'encarregaria de recollir els fons esmentats (29).

Foren també Llobet i Pi i Aramon qui el més d'abril del mateix any ja havien presentat a l'Ajuntament l'oferiment per ordenar i classificar els llibres davant de l'estat en què es trobaven, amuntegats a les dependències de Sant Joan, i exposats, com també explica Duran i Sanpere, a humitats i manca de ventilació. La tasca duta a terme, tot i que agraïda oficialment, no tingué més recompensa que aquesta perquè, un cop oberta al públic, fou nomenat per al càrrec de bibliotecari el gener de I 836 Josep Martí i Pradell, sacerdot i també membre de l'Acadèmia de Bones Lletres.

No obstant això, com informa novament Alcolea et al. (29) l'Acadèmia de Bones Lletres continuava aspirant a encarregar-se de la formació de la Biblioteca Pública amb els fons bibliogràfics desamortitzats i, així, en febrer de i 837 encara la trobem recordant a les autoritats competents la necessitat de fer complir la reial ordre que manava recollir els llibres dels convents suprimits perquè no havien arribat encara tots els fons, principalment els de Sant Cugat del Vallès i Montserrat. En aquest sentit, és interessant citar les paraules de Mateu i Llopis quan aborda aquest període: «El 6 de abril de 1837 quedaron instaladas en el Monasterio de San Juan la Real Academia, la Sociedad de Amigos del País y la Biblioteca que había de ser pública. Con esta decisión de la Academia se aspiraba a la utilización de su Biblioteca corporativa por parte de todos» (483484). No queda clar, a partir de les informacions reunides, si els fons recuperats dels convents i el de la corporació barcelonina han d'entendre's com un únic fons.

Segons Martí de Riquer, la possessió d'aquest antic recinte conventual donà molts maldecaps a l'Acadèmia: "pues el Jefe Político intentó arrojarla de allí, y cuando ya se había conjurado este peligro, comenzaron las protestas de las religiosas Maltesas, que reclamaban lo que era bien suyo» (297).

Aquests maldecaps tenen molt a veure, entre d'altres raons, amb la disputa per la direcció de la futura Biblioteca Pública. Sabem que a partir d'aquest moment comencen els enfrontaments amb altres societats per la custòdia dels fons bibliogràfics conventuals. Per exemple, davant de la pretensió de Fomento de la Ilustración que havia demanat a l'Ajuntament ser responsables de la futura biblioteca, l'Acadèmia, en sessió de 24 d'octubre de I 837 , hagué de recordar que aquesta tasca ja els havia estat encomanada a ells prèviament quan s'havien encarregat de la recuperació dels llibres després de la desamortització, i van acordar enviar a l'Ajuntament una comissió perquè defensés la seva posició (Alcolea et al. 3 I ). I, en efecte, la tasca de recuperació de materials bibliogràfics per part de la corporació barcelonina continuà, perquè el 23 de gener de i 838 el 
president de l'Acadèmia, en Bofarull, comunicà que ja tenien en el seu poder tots els manuscrits procedents de la biblioteca del convent de Sant Agustí.

La qüestió és que les disputes continuaren, la Biblioteca Pública passà de l'Ajuntament a mans de la Diputació per successius decrets i resolucions i, finalment, d'aquesta a la Universitat, que de manera definitiva custodia aquests fons des de l'any i 847. Abans d'arribar a aquesta resolució, continuaren, però, Acadèmia, Amics del País i Biblioteca Pública compartint espais, majorment per problemes econòmics que impedien el trasllat dels fons bibliogràfics, ocupant la biblioteca part del primer pis de les dependències santjoanistes. Davant de la necessitat de més espai per a la biblioteca, l'Acadèmia i els Amics del País, fora ja de concurs per la seva direcció, es mostraren poc disposats a cedir-li la totalitat del primer pis, fins que per Reial Ordre del 6 de maig de i 84 I ambdues corporacions van ser comminades a fer-ho. D’aquí a la seva definitiva sortida de l'edifici religiós només restà un pas, i així, el I 859, les dissensions per l'espai, també reclamat per les religioses malteses com recorda Riquer, arribarien a tal grau de conflictivitat que l'Acadèmia es veié obligada a abandonar les parets del convent de Sant Joan el i 860.

Vénen a partir d'ara uns anys de nomadisme durant els quals l'Acadèmia ocupà diferents dependències on se celebrarien les sessions $\mathrm{i}$ es guardaria la documentació: l'Ateneu de Barcelona, on ocupà una de les sales fins que aquesta es convertí en sala de lectura, unes dependències a la plaça del Rei, l'antiga sagristia de la capella de Santa Àgueda des de finals de i $877 \ldots$, fins que, per Reial Ordre del 7 de juliol de i9I7 d'Alfons XIII al Ministeri d'Instrucció Pública i Belles Arts, es disposava que la Reial Acadèmia passés a ocupar, per cessió, l'edifici del Palau Requesens, seu actual de la corporació barcelonina. Després dels treballs de restauració vist el mal estat de conservació de l'immoble, des de la primavera de I927, quedaren installats definitivament la Biblioteca i l'Arxiu.

\section{ELS FONS MEDIEVALS CATALANS DE LA BiBLIOTECA D'INTERÈS PER A BITECA}

El fons medieval que preserva actualment l'Arxiu-Biblioteca és ben petit: quatre manuscrits, de temàtica diversa, amb predomini de religió i filosofia moral, i són els següents:

- Ms. 3-I-7 miscelllani que conté:

I. Joan de Galles, Breviloqui o breu parlament dels antics prínceps e philòsoffs, f. viii-xix, CNUM 24I3.

2. [Anònim] D'aquestes dotze coses és tengut tot senyor a sos vassalls, $\mathrm{f}$. xixra-xixva, CNUM 24I4.

3. Antoni Canals, Scipió i Anibal, f. xx-xxviii, CNUM I609.

4. Lucius Annaeus Seneca, De providencia (tra. A. Canals), f. xxviii-xxxvv, CNUM I6IO. 
5. Pseudo-Pseudo-Bernardus Claravallensis, Epistola de gubernatione rei familiaris o Epistola de sant Bernat, sobre el regiment de la casa familiar, $\mathrm{f}$. xxxvi-xxxvii, CNUM 2300.

6. [Anònim] Consell de bones doctrines que una reina de França donà a una filla sua que fonch muller del rei d'Anglaterra, f. xxxvii-xxxviii, CNUM $230 \mathrm{I}$.

7. Alfons de Gandia i de Foix, Carta a la seva filla per a càstic i bons nodriments, f. xxxviiiv-xxxix, CNUM 24I 5 .

- Ms. 3-I-8 amb Albertanus Brixiensis, De arte loquendi et tacendi, o Tractat de bel parlar, f. Ira-I 2va, CNUM 2302.

- Ms. 3-II-20 que conté:

I. Francesc Eiximenis, Psalterium alias laudatorium o Saltiri laudatori, p. I-28I, CNUM I78I.

2. Guillem Fontana. O ànima mia: Gran compassió he de tu, p. 28 I, CNUM 2172.

3. Pseudo-Bonaventura / [Anònim] Exposició del Pare Nostre, l'Ave Maria i la Salve Regina, p. 28 I-378, CNUM I620.

- Ms. 3-III-7 amb Francesc Eiximenis, Vita Christi o Vida de Jesucrist, f. I-87v, CNUM 734.

De la procedència d'aquest petit fons medieval se sap ben poc; només un d'ells conserva un ex-libris a ploma, "de la biblioteca de sant agustí», mentre que de la resta no hi ha notícies. Per les raons que s'exposaran a continuació, i tenint en compte les vicissituds històriques per les quals passà l'acadèmia en la seva voluntat de formar una biblioteca, tot fa pensar que estem davant de còdexs tots procedents de dos convents desamortitzats (Sant Agustí i Santa Caterina) i que foren recuperats per la Comissió de l'Acadèmia designada per a tal tasca durant o poc abans de l'any i 838 .

Per tal de conèixer els fons que posseeix actualment l'arxiu-biblioteca, els investigadors només disposen d'un catàleg de fitxes manuals, per ordre alfabètic d'autors i matèries, consultable en sala $\mathrm{i}$ en el qual es consigna una mínima informació. Hi existeix, a més a més, un catàleg antic, del segle XIX, el manuscrit 3-III- I 6 que conté un Inventario de los objetos que se encuentran en el archivo de la Real Academia de Buenas Letras de Barcelona, establecido en una de las estancias de la Universidad Literaria (Duran, Repertori 472) i que no s'ha pogut consultar durant l'elaboració d'aquest treball perquè ha estat impossible localitzar-lo.

Deixant de banda aquests mínims, si hom se centra en els fons bibliogràfics provinents de la desamortització, es conserven alguns manuscrits a la Biblioteca de Reserva de la Universitat de Barcelona, tot ells dels segles xviII i començaments del xix, que guarden els inventaris i les catalogacions dels llibres que posseïen els convents, essent moltes vegades útils perquè ajuden a identificar la procedència d'un volum determinat, tot i que molts dels llibres conservats duen un ex-libris, normalment manuscrit, que en delata la procedència. També existeixen altres elements que ajuden a confirmar-la, com, per exemple, l'enquadernació, perquè els convents enquadernaven els llibres en un estil determinat (Verger). A 
excepció del ms. 3-II-2o que duu ex-libris de Sant Agustí com s'ha dit, malauradament, cap d'aquestes vies resulta útil, perquè no s'ha trobat cap catàleg o inventari dels llibres de l'antic convent per conèixer els fons que custodiava abans de l'exclaustració, i, pel que fa a la relligadura, a excepció de la Vita Christi d'Eiximenis, deslligada, els altres manuscrits conserven una relligadura en pergamí sobre cartró, un tipus d'enquadernació molt comuna.

Sí que ha resultat molt útil, però, davant d'aquesta mancança d'inventaris, el testimoni de primera mà del pare Jaume Villanueva Astengo (I765-I 824) i el seu Viage literario a las iglesias de España ( I 803-I 854).

Amb la finalitat d'elaborar una historia dels rituals litúrgics i les cerimònies religioses antigues d'Espanya (un De antiquis Hispanae Ecclesiae ritibus) en col-laboració amb el seu germà Joaquim Llorenç, l'historiador i dominic, per Reial Ordre del i 802 i amb la benedicció i ajut econòmic de Pedro Ceballos, secretari d'Estat de Carles IV, inicià un viatge que l'hauria de portar a visitar més de cent cinquanta arxius eclesiàstics «para que de los archivos y bibliotecas de comunidades del Reino recogiese los documentos convenientes» (Diccionario Biográfico 688). Al llarg dels gairebé sis anys que durà el periple, que es veié truncat l'any I 808 a causa de l'aixecament del 2 de maig i la Guerra del Francès, Villanueva viatjà per Catalunya, el País Valencià, les Balears i part d'Andalusia reunint la documentació que posteriorment enviava en cartes al seu germà i que integren els vint-i-dos volums de què consta l'obra.

D'aquests, els volums i 7, i 8 (publicats el i 85 I) i i 9 ( I 854 ) recullen les notícies sobre els arxius i biblioteques inspeccionats a Barcelona, on Villanueva visità i pogué estudiar, entre d'altres, els fons de la catedral de Barcelona, de l'Arxiu de la Corona d'Aragó i d'altres fons de titularitat llavors privada, ara llegats a institucions públiques (la biblioteca del Palau Dalmases, ara a la Biblioteca de Catalunya, i del Palau Requesens, al Casal Borja de Sant Cugat del Vallès a través de la Companyia de Jesús) i fons de convents (Sant Domènec, Sant Francesc, del Carme, Sant Agustí, etc.) que, com s'ha vist, pocs anys després i arran de la desamortització eclesiàstica passaren a formar les Biblioteques Públiques Provincials.

\section{Els fons dels convents de Sant Agustí i de Santa Caterina de Barcelona}

El fons del convent de Sant Agustí de Barcelona, d'acord amb Villanueva, fou un dels que més experimentà el rigor dels esdeveniments històrics, perquè primer amb la Guerra de Successió i després amb el trasllat de l'any I 727 havia perdut gran part de les seves antiguitats ( I 7 I). Al marge de la biblioteca, espaiosa i neta, però pel que sembla mancada d'un bibliotecari que ordenés els manuscrits $\mathrm{i}$ les miscel-lànies modernes, bona part dels llibres descrits pel dominic els veié en una altra dependència de l'esmentat convent: a la cellla del pare mestre exprovincial Fr. Juan Izquierdo, amb una biblioteca descrita per Villanueva on 
«descuellan buenos manuscritos» (172). Cita, entre d'altres, uns Usatges de Barcelona i uns exemplars manuscrits del major interès per a nosaltres:

Item un códice vit. fol. que comprende el tratado lemosin de la batalla de Scipio, obra de Fr. Antonio Canals de mi órden, el mismo de que ya diré en la biblioteca de los PP. Descalzos. Del mismo autor el tratado de Seneca é Providencia, dirigido al molt é noble Mossen Ramon Boil, Gobernador general del regne de Valencia. Consta de nueve capítulos. = Traduccion lemosina de aquella carta atribuida á San Bernardo en la biblioteca de los Descalzos. = Una carta con este título: La letra deval scrita feu lo Marques de Villena é Compte de Ribagorza, qui apres fo intitulat Duch de Gandia, per Donna Johanna, filla sua, quant la maridà ab Don Johan, fill del Compte de Cardona per la qual li scribi castich é bon nodriments, dient axi: ara filla, etc. ... Vi tambien allí mismo vertidos en lemosin y del siglo xv los dos tratados de Albertrano de Brescia De doctrina dicendi et tacendi, y el Liber consolationis et consilii. El primero se dice allí escrito en I 2 I 5 , y el segundo por equivocacion en M.CCC.XLVI. pues debe ser en I 240. De estos opúsculos se volverá á hablar en los de los PP. Carmelitas (Villanueva 172-173).

El primer manuscrit és l'actual 3-I-7 de l'Acadèmia i el segon text que cita el pare Villanueva, el Tractat de bel parlar de Brescia, és el ms. 3-I-8.

En el cas del primer, resulta més fàcil de provar. El 3-I-7 ha estat estudiat i parcialment editat per Rosanna Cantavella, que destaca el caràcter miscellani del manuscrit a partir d'un criteri temàtic, arreplegant textos relatius a la cultura i l'educació de la dona (33-36). No existeix cap altre manuscrit amb les mateixes obres que integren el present recull, de fet tres dels textos són testimoni únic («D’aquestes dotze coses és tengut tot senyor a sos vassalls», «Consell de bones doctrines que una reina de França donà a una filla sua que fonch muller del rei d'Anglaterra» $\mathrm{i}$ «Carta a la seva filla per a càstig $\mathrm{i}$ bons nodriments» d'Alfons de Gandia i de Foix).

La primera edició d'aquests mateixos textos i altres la signava Antoni de Bofarull, el qual, sota el títol de «Opúsculos catalanes», donà a conèixer part del contingut del manuscrit al volum in de les Memòries de la Real Acadèmia de Buenas Letras de Barcelona l'any i 868. Sens dubte, amb la seva publicació, Bofarull acomplia un dels vells propòsits de l'Acadèmia després de la recollida dels llibres de convents: publicar els dignes de veure la llum, com havien manifestat en aquell ja llunyà $\mathrm{I} 835$.

En el cas del ms. 3-I-8, se'n conserven dos testimonis més, un a la Biblioteca Bartolomeu March de Palma de Mallorca (ms. 87-V3-9, Manid I 387 ) i l'altre a la Biblioteca de Catalunya (ms. 42, Manid I365), ambdós de caràcter miscellani. L'exemplar que descriu Villanueva fa pensar que el De doctrina dicendi et tacendi era un unicum, d'altra banda i seguint l'ús habitual, hauria proporcionat els altres títols preservats en el volum descrit. També aquesta obra fou editada per Antoni de Bofarull en els seus opuscles.

Per acabar, i tornant a l'exemplar de la Vita Christi de Francesc Eiximenis, cal assenyalar que, a diferència dels altres tres manuscrits de la biblioteca de l'Acadèmia, no hi ha cap ex-libris o font bibliogràfica que el relacioni amb el 
convent de Sant Agustí, car és probable que, si el pare Villanueva l'hagués vist, ho hauria consignat en les seves lletres com fa, per exemple, amb els manuscrits del menoret que veié al convent de Santa Caterina. Rebut en aquest, el dominic informa que «abunda esta biblioteca de códices preciosos y raros, cuya noticia puede interesar á los literatos» (176). En efecte, la biblioteca de Santa Caterina posseïa uns 22.000 volums, molts dels quals es perderen $\mathrm{i}$ uns altres passaren a la Biblioteca Pública. En concret, destaca Villanueva «Del célebre Don Francisco Eximeniz hay el Vita Christi, y el libro de las Donas, manuscritos del siglo xv. Otro vol. fol. contiene estos escritos del mismo; es á saber: Tractat de providencia sobre consell ... Siguen en el mismo volúmen: Petita obra, que tracta per recobrar é haver lo exercisci de moderacio. $=L$ 'art de ben morir. $=L$ a confessio» (I77) i conclou la relació d'obres eiximenianes afegint: "Abundan por acá las obras manuscritas de este sabio escritor, y apenas hay biblioteca donde no se hallen» (I78).

La darrera obra descrita pel pare Villanueva és l'actual manuscrit 80 de Reserva de la Biblioteca de la Universitat de Barcelona, que conté el Llibre de les dones d'Eiximenis, l'anònim Art de bé morir, el De providència sobre consell d'Albertanus Brixiensis, i els Ensenyaments dels vicis $i$ virtuts que forma part del llibre segon del Tresor de Brunetto Latini.

Quant al primer títol mencionat, la Vita Christi, fou identificada per Jaume Massó i Torrents en el seu ja clàssic assaig de bibliografia eiximeniana dels anys I909-1910, amb el manuscrit i I60 que es conserva a la Biblioteca de Reserva de la Universitat de Barcelona. Massó, però, no consultà un segon manuscrit fragmentari, el I925, que sí recull més tard David J. Vieira (293) en les seves addicions als manuscrits no catalogats (293) per Massó i Torrents i que Mateu Ibars (84) creu procedent del mateix convent dominic que el manuscrit i i6o.

El manuscrit 1925 és un volum fragmentari que comparteix amb el de Bones Lletres moltes característiques codicològiques: format, foli, mides, el material d'escriptura (paper), disposició a dues columnes, mateixa decoració, mans que copien el text, filigrana (la muntanya de tres cims) i tots dos tenen la particularitat de conservar les rúbriques anotades a ploma per al rubricador als marges en lletra de cos petit. Tot ens fa pensar que es tracta del mateix manuscrit que es podria reconstruir a partir del seu contingut:

\begin{tabular}{|c|c|c|}
\hline MANUSCRIT & FOLIACIÓ MODERNA & Contingut \\
\hline ResBUB I925 & f. Ira-Ivb & Llibre III, cc. XVIII-XX \\
\hline BibRABLB 3-III-7 & f. Ira-87vb & $\begin{array}{l}\text { Llibre III, c. XXII (final) - } \\
\text { Llibre IV, c. LII (incomplet) }\end{array}$ \\
\hline ResBUB I925 & f. $2 r a-28 v b$ & $\begin{array}{l}\text { Llibre IV, cc. LX-LXI, frag- } \\
\text { mentaris }\end{array}$ \\
\hline
\end{tabular}


El fragment de Bones Lletres s'hauria de situar entre el primer i el segon foli del manuscrit I925, que en aquest no tenen continuïtat. Si no es tracta del mateix manuscrit, podem suposar que eren manuscrits bessons produïts en un mateix taller.

En definitiva, la conservació d'aquests quatre manuscrits a les dependències de l'Acadèmia de Bones Lletres s'ha d'atribuir a la gran tasca de recuperació del patrimoni cultural català duta a terme per alguns dels seus membres durant la primera meitat del segle XIX.

$$
\begin{aligned}
& \text { LOURDES SORIANO ROBLES } \\
& \text { IRCVM (Institut De ReCERCA EN CUltures Medievals) - } \\
& \text { UB (Universitat de Barcelona) }
\end{aligned}
$$

\section{REFERÈNCIES}

Alcolea, Santiago, Dolors Lamarca, Pilar Llopart i Jordi Torra. La Biblioteca de la Universitat de Barcelona. Barcelona: Publicacions de la Universitat de Barcelona, I994.

Bofarull, Antoni de. «Opúsculos catalanes». Memorias de la Real Acadèmia de Buenas Letras de Barcelona 2 (I 868): 529-6I 3.

Campabadal i Bertran, Mireia. La Reial Acadèmia de Bones Lletres de Barcelona en el segle XVIII. L'interès per la història, la llengua i la literatura catalanes. Barcelona: Reial Acadèmia de Bones Lletres i Publicacions de l'Abadia de Montserrat, 2007. Textos i Estudis de Cultura Catalana I 9 .

Cantavella, Rosanna. «L'educació femenina per al matrimoni: dos opuscles catalans medievals». Estudis de Llengua i Literatura. Miscellània Joan Fuster. Vol. IV. Ed. a cura d'Antoni Ferrando i Albert G. Hauf. Barcelona: Universitat de València, Associació Internacional de Llengua i Literatura Catalanes i Publicacions de l'Abadia de Montserrat, 1991. 33-57.

Comas, Antoni. «L'Acadèmia». Història de la literatura catalana. Vol. 4. Barcelona: Ariel, 1964. 76-103 i I 23-146.

Diccionario Biográfico del Trienio Liberal. Dir. Alberto Gil Novales. Madrid: El Museo Universal, I99I.

Duran i Sanpere, Agustí. Barcelona i la seva història. L'art i la cultura. Barcelona: Curial, I975. 559-562. Documents de Cultura. [Primera versió del text publicada a Barcelona. Divulgación Histórica 5 (I948)].

Massó I Torrents, Jaume. «Les obres de Fra Francesch Eiximeniç (I 340?I 409?). Essaig d'una bibliografia». Anuari de l'Institut d'Estudis Catalans 3 (I909-1910): 588-692.

Mateu Ibars, Josefina. «Los manuscritos de los siglos xv y xvi de la Biblioteca 
Provincial y Universitaria de Barcelona». Biblioteconomía 73-74 (I97I): 63-I4I.

Mateu i Llopis, Felip. «El archivo, la biblioteca y el museo de la Real Academia de Buenas Letras». Boletín de la Real Academia de Buenas Letras de Barcelona 25 (I953): 48I-49I.

Miquel Rosell, Francesc. Inventario general de manuscritos de la Biblioteca Universitaria de Barcelona. Madrid: Direcciones Generales de Enseñanza Universitaria y de Archivos y Bibliotecas, I958-1969. 4 v.

Repertori de manuscrits catalans (I474-I620). Vol. III. Dir. Eulàlia Duran. Barcelona: Institut d'Estudis Catalans, 2003. Memòries de la Secció HistòricoArqueològica 60.

Riquer, Martí de. «Breve historia de la Real Academia de Buenas Letras de Barcelona». Boletín de la Real Academia de Buenas Letras de Barcelona 25 (1953): $275-304$.

Soriano, Lourdes i Glòria SABATÉ. «D'inèdits i retrobats: el Llibre dels àngels, la Vida de Jesucrist de Francesc Eiximenis i el context de la seva difusió». Boletín de la Real Academia de Buenas Letras de Barcelona 49 (2003-2004): 447-46I.

Verger Arce, Neus. «La Biblioteca de Reserva de la Universitat de Barcelona». BiD. Textos Universitaris de Biblioteconomia $i$ Documentació $2 \mathrm{I}$ (2008). <http://www.ub.edu/bid/2 I/verger.htm> (consulta: abril 20I0).

VIERA, David J. «Manuscritos eiximinanos no catalogados por J. Massó Torrents». Estudios Franciscanos 80 (1979): I 57-165. Reproduit a Studia Bibliographica. Estudis sobre Francesc Eiximenis I. Girona: Collegi Universitari de Girona i Diputació de Girona, I991. 289-296.

Villanueva y Astengo, Jaime. Viage literario a las iglesias de España. Tomo XVIII. Viage á Barcelona. Madrid: Imprenta de la Real Academia de la Historia, I 85 I. 


\section{APÈNDIX II \\ DESCRIPCiÓ DELS MS. MEDIEVALS DE LA BiBLIOTECA de la Reial Acadèmia de Bones Lletres de Barcelona}

MANID i 943. Barcelona: Bones Lletres, 3-I-7. Copiat i 40 I-I450. Format: foli. MATERIAL: pergamí. Foliació: 33 (= viii-xl) f. Foliació moderna a llapis, en xifres aràbigues; antiga foliació en xifres romanes, tallada per la guillotina del relligador. CoL·LACIó: I darrer foli d'un quadern de 8 bifolis (amb reclam) $283848 \quad 54 \backslash / 3$; reclam horitzonal al marge dret inferior, en filacteri. Mides de la p.: 360 x $250 \mathrm{~mm}$.; de la caixa: 267 x 168 mm., de la columna 267 x 75.16 .78 mm., col.: 2; núm. de línies: 55 ll. (mides preses al foli I). Lletra: dues mans gòtiques libràries, la primera $f$. viii-xxxviir; la segona $f$. xxxviixxxix. Justificació: de règim complet fins al foli xxxvi, més senzilla a partir del foli següent coincidint amb el canvi de mà. Justificació: de règim complet, a punta seca, que ha deixat traç. A partir del foli xxxvij no s'observa el règim complet i la decoració és més senzilla, tot coincidint amb el canvi de mà. No s'observen perforacions. Primera línia escrita. Decoració: (f. I-36): caplletres inicials de parts embotides en vermell i blau i amb decoració filigranada en vermell i lila; resta de caplletres de 3 unitats de pautat, en vermell i blau alternant i decoració filigranada en lila i vermell que també alterna; calderons alternant en vermell i blau i tocs de groc en les majúscules i caplletres amb decoració de filigrana en blau i vermell (menys a les dues darreres peces del volum). Condició: marges en mal estat. Volum malmès per la humitat, sobretot es veu afectat el llom en la seva part superior i inferior. Dos primers folis conservats molt malmesos $i$ despresos de la relligadura. Notes: el 2003 no es trobava el manuscrit i les dades foren extretes de reproduccions fotogràfiques del manuscrit. Bibliografia: Cantavella (I99I), «L'educació femenina per al matrimoni: dos opuscles catalans medievals», esp. p. 34-6 (esp.). Kristeller (1989), Iter Italicum. Accendunt alia Itinera. A Finding List of uncatalogued or incompletely catalogued bumanistic Manuscripts of the Renaissance in Italian an other Libraries (Alia Itinera II) Great Britain to Spain, vol. IV, p. 684. March (I993), Obra completa, p. I9. Marnierre (1999), Inspecció personal. Sabaté (2004), Inspecció personal. Sabaté i Soriano (2010), Inspecció personal.

f. viii-xix. TEXID 1986. Johannes Gallensis. Breviloquium de virtutibus antiquorum principum ac philosophorum. Títol traduit: Breviloqui o breu parlament dels antics princeps e philòsoffs. CNUM 24I3. [inc. text $\mathrm{f}$. viii] deus e los pobles son fets ydolatres. [expl. text f. xixrb] Lo rey iusticier es garda dela ley honor del poble endresament del regne. Arbre diuinal sots la ombra del qual se reposen los cansats fflacs Afflegits E treballats. [colofó] Ffinito libro sit laus gloria xpo amen. Condició: fragment. BibliogrAFIA: Gal.les (1930), Breviloqui, p. 76-7.

f. xixra-xixva. TEXID 2725 . Anònim. D'aquestes dotze coses és tengut tot senyor a sos vassalls. CNUM 24I4. Títol: D’aquestes dotze coses es tengut tot senyor a sos vasalls. [rúbrica xixrb] daquestes dotze coses es tengut tot senyor a sos vassalls. [inc. text] La primera es quells tingua en pau... [expl. text xixva] lo mariner leuger e de bon manament. E lescriua leal e apte.

f. xx-xxviii. TEXID i 838. Antoni Canals. Scipió $i$ Anibal. CNUM r609. [inc. rúbrica xxra] En nom de nostre senyor deu jesu crist [expl.] comensa lo preambol ala obra deius scrita. [inc. dedicatòria] A6L molt alt senyor lo senyor don alfonso duch de gandia ffra- 
re anthoni canals del orde dels frares preycadors... [expl. dedicatòria xxjvb] massa affectadament estar uiure e preseruar en diuisions bregues guerres e bathalles [rúbrica index] Rubrica dels capitols del present tractat [inc. index] Primer capitol com anibal trames aspies a mirar la host dels romans [expl. index xxijra] scipio affrica fon uen[çut] [rúbrica text] Primer Capitol com anibal trames aspies a mirar la host dels romans dela qual era capita scipcio affrica [inc. text] $\mathrm{C}_{7} \mathrm{Om}$ anibal uehe lo grant poder de scip $\backslash \mathrm{i} / \mathrm{o}$ que hera molt en gents darmes... [f. xxviiijrb expl.] E sobre lo sepulcre seu es escrit. Aci jau anjbal lo gran guerrer. Bibliografia: Bofarull (i 868), «Opúsculos catalanes», Memorias de la Academia de Buenas Letras de Barcelona, p. 532-60. Canals (1935), Scipió e Aníbal. De providència (de Sèneca). De arra ànima (D'Hug de Sant Víctor), p. 26, it. A. Kaeppeli (1970-80), Scriptores ordinis praedicatorum Medii Aevi, vol. I, p. I08.

f. xxviii-xxxvv. TEXID i917. Lucius Annaeus Seneca. De providència. Altres títols de l'obra: De providència sobre consell. CNUM i6 10 . [inc. rúbrica xxviiivb] Prolech daquest libre apellat libre de senecha de prouidencia. [inc. dedic] A $5 \mathrm{~L}$ molt alt noble mossen Ramon boil Gouernador general del regne de ualencia [expl. xxiira] los sants angels quius illuminen lo enteniment e us inflamen lo cor com legirets lo dit libre Amen. [inc. ind.] Primer capitol que totes les coses son subiugades a la diuinal prouidencia [expl.] Nouen capitol que deus respon ala principal questio e mostra que null temps al bon hom ans lo y remou. [inc. tít.] $\mathrm{C}_{4} \mathrm{O}$ mensa lo libre de senecha de prouidencia e fundas sobre la següent questio com lo mon sia regit per la prouidencia diuinal [expl.] que los bons homens sostinguen mal. Primer capitol que totes les coses son subiugades a la prouidencia diuinal. [inc. text] $\mathrm{U}_{3} \mathrm{Na}$ questio meas feta [expl. xxxvva] auets temor dela cosa qujs fa tantost per cert massa temets. [inc. colofó xxxvv] Ffinito libro sit laus gloria Xpo. Amen. Bibliografia: Bofarull (i 868), «Opúsculos catalanes», Memorias de la Academia de Buenas Letras de Barcelona, p. 56 I-80. Canals (1935), Scipió e Aníbal. De providència (de Sèneca). De arra ànima (D'Hug de Sant Víctor), p. 27.

f. xxxvi-xxxvii. TEXID I 436. Pseudo-Bernardus Claravallensis. Epistola de gubernatione rei familiaris. Títol traduit: Epistola de sant Bernat, sobre el regiment de la casa familiar. Altres títols de l'obra: Lletra a Ramon de Castell Ambròs. CNUM 2300. [inc. rúbrica xxxvira] Epistola de sant bernat del regiment e cura dela casa feta al Caualler Ramon de Castell ambros. [inc. text] $\mathrm{A}_{4} \mathrm{~L}$ gracios e benauenturat caualler reuerent mossen Ramon de Castell ambros [f. xxxviira expl.] al qual la ha portada la sua dampnada uellea. Bibliografia: Bofarull (i 868), «Opúsculos catalanes», Memorias de la Academia de Buenas Letras de Barcelona, p. 58I-59I.

f. xxxvii-xxxviii. TEXID 2643. Anònim. Consell de bones doctrines que una reina de França donà a una filla sua que fonch muller del rei d'Anglaterra. CNUM 2301. [inc. rúbrica xxxvii] Conseyll de bones doctrines que una reyna de frança dona a.j. filla sua que fonch muller del Rey danglaterra. [inc. text] $\mathrm{U}_{4} \mathrm{Na}$ regina hague en frança la qual romas vidua [f. xxxviii [expl.] Placia ha nostre senyor deus que aytal façen totes les altres dones e donzelles qui aço ligiran ne hoyran dir. Amen. Deo gracias. Bibliografia: Cantavella (I99I), «L’educació femenina per al matrimoni: dos opuscles catalans medievals», p. SI I-s I 4 (ed.).

f. xxxviiiv-xxxix. TEXID 2724. Alfons de Gandia i de Foix. Carta a la seva filla per a càstic $i$ bons nodriments. CNUM $24 \mathrm{I} 5$. [inc. rúbrica xxxviiiva] La letra deual scrita feu lo marques de uillena e compte de Ribagortça qui apres fo intitulat duch de Gandia. per 
dona Johana filla sua quant la marida ab don johan fill del compte de cardona. per la qual li scriuj castich e bons nodrimentz dient axi. [inc. text] $\mathrm{C}_{4} \mathrm{ARA}$ filla yo fas Gracies adeu com a ell ha plagut que yo axi com apare vostre [f. xxxixra [expl.] e ab tant lo Sant Sperit uos tingua en sa guarda. Amen. Bibliografia: Cantavella (I99I), «L’educació femenina per al matrimoni: dos opuscles catalans medievals», p. 55-57 (ed.).

MANID 22 I 7. Barcelona: Bones Lletres, 3-I-8. Copiat i 30I [?]-I 400 [?]. Format: foli. MATERIAL: pergamí. Foliació: i6 (= III + I-I 5 + II) f. Col-LACió: il 8 24/3; sense reclams. Mides de la p.: 377 x 249 mm f. I; de la caixa: 252 x I $85 \mathrm{~mm}$; de la col.: 252 x 85 $\mathrm{mm}$, col.: $2 \mathrm{f}$. I-I 5 ; núm. de línies: $40 \mathrm{f}$. Ira. Lletra: gòtica rodona. Pauta: justificació a punta seca (al foli 9, marge extern, per exemple, s'observa una perforació de punxó). Primera línia en blanc, a vegades trepitjada; no s'observen perforacions. Decoració: caplletres en tonalitats morades i marrons, amb decoració filigranada en blau i vermell; calderons violetes, separació de paràgrafs en vermell, passatges subratllats en vermell (sentències); algunes majúscules decorades amb tocs de color ocre. Condició: òptim estat de conservació, tret d'alguna taca d'humitat al centre del volum i algun foradet. Folis I 3-Is en blanc. Adhesiu a l'interior de la coberta anterior: «PERTENECE A LA | ACADÉMIA DE BUENAS LETRAS | DE | BARCELONA». A mà, afegit a llapis: "Alberta de Brescia | Bretaña». Relligadura: antiga, pergamí sobre cartó. Notes: Antoni de Bofarull el considerava ms. del segle xiII. Bibliografia: Sabaté (2002), Inspecció personal. Sabaté (2004), Inspecció personal. Soriano (2010) Inspecció personal.

f. Ira-I 2va. TEXID I 426. Albertanus Brixiensis. De arte loquendi et tacendi. Títol traduï: Tractat de bel parlar. CNUM 2302. [inc. rúbrica I ra] A4ci comença lo libre lo qual ha compost mestra alberta de Bretanya lo qual tracta dela doctrina de ben parlar pregant ala misericordia de deu que en lo comencament e en la fi de aquesta obra sia present la gracia del sperit sant. [inc. text] $\mathrm{P}_{3} \mathrm{Er}$ ço com molts en lo lur parlar erren e no es negu qui la sua lengua puxa domar [f. I 2va [expl.] la qual te narrada e comptada que el nos vulle ens faça venir als guoigs celestials amen. [inc. colofó] Explicit liber de doctrina dicendi et tacendi ab albertano Causidico brisen de hora sancte agathe composita et copilata sub. M. cc. xv. Jn mense decembris. Bibliografia: Bofarull ( I 868), «Opúsculos catalanes», Memorias de la Academia de Buenas Letras de Barcelona, p. 59I-6I3. Sabaté (2003), Inspecció personal.

MANID 20I9. Barcelona: Bones Lletres, 3-II-20 Olim: A 3-III-I. TÍtol al teixell: Eximeic [sic] | Libre de la hor | de Deu | Z-s-II. EXIMEIC [sic] | LIBRE | DE LA HOR I DE DEV || Z | s | .II.; el títol gravat al teixell en daurats, l'antiga signatura a ploma CopIAT I460-I 500. Format: Quart petit Material: paper. Foliació: I94 $(=\mathrm{I}+\mathrm{I}$-I $87+6) \mathrm{f}$. FOLIACIÓ: I + I-28 I + 2-[97] manca el 97 per numerar, arriba fins al 96 + VII. Col·LACIó: I-7I 2 8IO 9-I4I 2 I 54/5 i un final I64/5 (manquen p. 78-79, corresponents al primer foli del quadern 4 amb pèrdua dels dos darrers folis del quadern), sense reclam perquè manquen els dos darrers folis; reclams horitzontals centrats al marge inferior del foli. Mides de la p.: 20 I X I 3 I $\mathrm{mm}$ f. I; de la caixa: I 20 x $80 \mathrm{~mm}$. 2 I ll. LlETRA: gòtica rodona f. I-IO5; altra mà gòtica rodona f. I06-I07. Filigranes: flor de magraner a la p. 3 semblant Briquet 6655 doc. Palermo: I462, var. Pisa: I464-I469, Peruggia: I456 i I458; flor semblant a Briquet 6644 doc. Roma: I 443-I 447, var. Firenze I 444-I 446, var. Pisa I 445-I 448. PAUTA: a mina de plom, de règim complet, amb línies de guia per als renglons, primera línia escrita i quatre cinc comptant una al marge dret, a l'alçada de la primera línia; perforacions rodones als angles de la caixa. Decoració: dues inicials (de 4 unitats de pautat les 
que inicien tractat, la resta de 3 unitats de pautat) decorades al començament dels tractats (p. I i 2, (282 si continuem la primera paginació) de sis i cinc unitats de pauta respectivament amb motius vegetals, en vermell, blau, verd, blanc i or, la segona amb ocellets dibuixats als marges esquerre i inferior; la resta de caplletres són en vermell i blau, semblen haver estat concebudes com a bipartides però no s'han completat i resten totes elles alternant en vermell i blau sense decoració filigranada, lletres majúscules safranades i rúbriques en vermell; al darrer tractat indicacions de versicles en verd. Condició: quaderns despresos, molts folis també; un post-it a la coberta anterior indica, a març de 20I0, «Per restaurar» així com els primer i darrer folis del I4. Els sis últims folis estan en blanc. No hi a numeració per quaderns, i el volum està paginat (només indicant la numeració corresponent al recto del foli). Errades a la paginació: 54 (per 55) i a partir d'aquí continua la paginació al recto del foli en xifres parells, no senars. Entre les pàgines 94 i 96 de la primera part, llacuna al text, ja que el reclam es llegeix «porta», i el foli següent no comença per aquesta paraula (potser el copista ha oblidat copiar la paraula [?] iniciant el quadern següent: «que los dimonis hauien en les anjmes ell ha vberta la [porta] II dela vida eternal. Aquest es»). Salt en la numeració: de la pàgina 224 recto salta a la 228 recto (per 226). El segon text comença a la p. 2 (no hi cap pàgina $\mathrm{I}$; l'anterior està numerada al verso 28I). A la p. 80 de la segona part, es llegeix «Aqui falta mitja fulla y al fi l'altra mitja» advertint de la manca d'un foli el primer del quadern que correspondria a les pàgines 78 79, i a l'última pàgina la mateixa mà adverteix: «Manca la darrer mitja fulla». RELLIGADURA: pergamí sobre cartó, desfeta, segons Puig i Oliver de finals del segle Xvi o inicis del segle XVII. Procedència: Barcelona: Convent de Sant Agustí (a la primera contraguarda hi ha un ex-libris del segle xviII: «Pertinet ad Conv. S. Augustini Barcinonem»; procedeix de la biblioteca del prior cf. Wittlin)), i 835 (olim Z-5-II). Notes: volum que recull obres procedents de la mateixa biblioteca. Bibliografia: Codina i Formosa (?), Transcripció dels folis I-28I del Ms. de la Biblioteca de la Real Acadèmia de Bones Lletres de Barcelona que conté el Saltiri d'Eiximenis traduït per Guillem Fontana. Marnierre (1999), Inspecció personal. Puig i Oliver (2010). Inspecció personal. Sabaté (2004), Inspecció personal. Vives (1955), «Exposición medieval del Pater Noster en traducció catalana de Fray Antonio Canals», Analecta Sacra Tarraconensia, p. I34-I35. Wittlin (1987-1988), «Un centenar de oraciones del Psalterium (alias laudatorium) de Francesc Eiximenis traducidas al catalán por Guillem Fontana en I 416, con una oración original», Boletín de la Real Academia de Buenas Letras de Barcelona, p. 179, it. Ms. D.

p. I-28 I. TEXID I 509. Francesc Eiximenis. Psalterium alias laudatorium. Títol traduït: Saltiri laudatori. Altres títols de l'obra: Psaltiri laudatori. CNUM I78 I. [inc. rúbrica f. I] Comença lo prolech del present libre dirigit per mestre ffrancesch Eximeniç del orde dels frares menors al Reuerent pare en Christ lo bisbe de teraçona. Lo qual libre es appellat flor del psalteri e en altra manera de lahor de dev. [inc. dedic] A6L molt reuerrent Reuerent pare en christ e senyor [expl. p. 3] remogut e foragitat. Comensa donchs la dita lahor de nostre senyor deu en la forma seguent [rubr. p. 3] En aquest psalm es demanat que sia donada gracia al peccador migensant la qual haia lo cors abil [sic] e dispost en loar nostre senyor en les sues excellencies e magnificencies [inc. text f. 3 ] $\mathrm{C}_{4}$ Reador de totes coses que es deu vertader e virtuos [f. 28 I expl.] per la qual me pusque acostar atu en la present vida per gracia e en la sdeuenjdora per gloria Amen. Condició: incomplet. Notes: no conté el pròleg del traductor ni la dedicatòria a madona Agnès, sí la d'Eiximenis al bisbe de Taraçona. Bibliografia: Massó i Torrents (I909-I9Io), «Les obres de Fra Francesc Eiximeniç (1340?-I409?). Essaig d'una bibliografia», Anuari de l'Institut d'Estudis Catalans, p. 675, it. i 85 (Ms. D). 
p. 272-28I. TEXID 2536. Guillem Fontana. O ànima mia: Gran compassió be de tu. CNUM 2172. [inc. text f. 272] $\mathrm{O}_{3}$ Anjma mja gran compassio he de tu per tant com veig que es posada en sobres grans agusties e tribulacions... [expl.] per la qual me pusque acostar a tu en la present vida per gracia e en la sdeuenjdora per gloria Amen.

p. 28 I-97 (segona part). TEXID i 857. Pseudo-Bonaventura; Anònim. Exposició del Pare Nostre, l'Ave Maria i la Salve Regina. CNUM 1620. [inc. rúbrica escrita aprofitant l'espai en blanc de la pàgina $28 \mathrm{I}$ ] Titol o preambol en les exposicions seguents. Co [sic] es primerament en la oracio. Aue marie gracia plena Pater noster qui es Salue regina misericordie. [inc. pròl. p. 2] A $5 \mathrm{~L}$ molt honorable mossen P. dartes Caualler mestre Racional del S. R. en Marti ffrare anthoni canals [p. I 2 expl.] e en la gloriosa mara sua que null temps sien sepparats de lur amor e gracia. amen. [rúbr.] Contemplacio molt deuota sobre la salutacio angelical la qual es Aue Maria. Aue maria gracia plena [inc. text p. I2] $\mathrm{A}_{3} \mathrm{Tu}$ senyor deu meu faç aquellas gracias que pusch dela pregonea deles mjes entramanas per ço com has volgut pendre e hunjr a tu nostra... [p. 97 expl.] O clement aconsolant dolça alletant. O clement en la obra piadosa en la affectio dolça en. Condició: incomplet. Bibliografia: Kaeppeli (I970-I980), Scriptores ordinis praedicatorum Medii Aevi, vol. I, p. I07. Vives (1955), «Exposición medieval del Pater Noster en traducció catalana de Fray Antonio Canals», Analecta Sacra Tarraconensia, p. I40- I 56 it. (ed.). Vives (1956), «Exposiciones del “Ave Maria” y "Salve” en traducción catalana de Fray Antonio Canals», Analecta Sacra Tarraconensia, 80-94, it. (ed.).

MANID i 530 . Barcelona: Bones Lletres 3-III-7 Olim: V. Copiat i 40 I-I 500 . Format: Foli gran. MATERIAL: paper. Foliació: $87(=\mathrm{I}-87) \mathrm{f}$. folis actuals, numerats modernament en xifres aràbigues a llapis; restes d'una antiga foliació a ploma en romans que no es correspon amb l'actual (f. I7 mod. = ant. 45 ; f. I 8 mod. = 46 ant.; f. $2 \mathrm{I}$ mod. antic 49). Col-lació: i i 6 2-5 I6 67/0 només es conserven els 7 primers folis del quadern, talons dels folis arrencats; reclams horitzontals centrats al marge inferior a l'intercolumni. MIDEs de la p.: 405 x 288 mm. f. i7; de la caixa: 296 x I 78 mm; de la col.: 296 x 79 mm, col.: 2; núm. de línies: $42 \mathrm{f}$. I7. Lletra: gòtica cursiva amb trets de la bastarda de dues mans, amb canvi de mà que comença a copiar al foli $77 \mathrm{vb}$, a partir de la quarta línia. FILIGRANEs: muntanya de tres cims amb creu. PAuTa: justificació a mina de plom, vuit perforacions rodones, fetes probablement amb punta de compàs, als angles de la caixa d'escriptura de les columnes i primera línia escrita. DecorAció: caplletres inicials de capítol de dues unitats de pautat, alternen en vermell i blau, amb decoració filigranada en lila i vermell; rúbriques i calderons en vermell; indicacions de les rúbriques al marge dels folis en tinta marró, per al rubricador. Condició: taques d'humitat, alguns folis malmesos, sobretot el primer i el darrer. Del foli 63 només se'n conserva un bocí, la cantonada interior superior; correccions del text al marge. Relligadura: deslligat, cobertes caigudes, són visibles els quatre nervis de la relligadura; actualment conservat dins d'una caixa de cartó folrada amb tela marró. Notes: es donava per perdut des de la Guerra Civil, romania a la biblioteca com una Vida de la Verge. Bibliografia: Casanovas (1906), "Còdecs de l"Arxiu del Palau», Revista de Bibliografia Catalana, p. I6-ı8, it. 5. Massó i Torrents (1909-I9I0), «Les obres de Fra Francesc Eiximeniç (I340?I 409?). Essaig d"una bibliografia", Anuari de l'Institut d"Estudis Catalans, p. 76, it. I 5 (Ms. B). Sabaté et al. (2004), "D”'inèdits i retrobats: el Llibre dels àngels, la Vida de Jesucrist de Francesc Eiximenis i el context de la seva difusió», Boletín de la Real Academia de Buenas Letras de Barcelona. 
f. I-87v. TEXID i 520. Francesc Eiximenis. Vida de Jesucrist. Altres títols de l'obra: Vita Christi. part I-v, segons Casanovas, actualment es conserva part del III i del IV tractat. CNUM 734. [inc. text f. I] [...] hom qui fills hauia qui visques be car la millor e la pus durabla hetat que hom podia dar ne lexar a sos fills era que hagues be viscut [f. $87 \mathrm{rb}$ expl.] e fahia contjnents de fembra qui va en part e soptosament corrent los detras crema e destrouj [...]. Condició: incomplet. Bibliografia: Rubió et al. ed. (195 I), El naixement de l'Infant Jesús. Transcripció i pròleg de.... Sabaté et al. (2004), "D'inèdits i retrobats: el Llibre dels àngels, la Vida de Jesucrist de Francesc Eiximenis i el context de la seva difusió», Boletín de la Real Academia de Buenas Letras de Barcelona. = BOOCT 734. 